\title{
Astrocytic CCAAT/Enhancer Binding Protein $\delta$ Regulates Neuronal Viability and Spatial Learning Ability via miR-135a
}

\author{
Yu-Yi Chu ${ }^{1}$ - Chiung-Yuan Ko ${ }^{2,7}$ • Wei-Jan Wang ${ }^{3} \cdot$ Shao-Ming Wang ${ }^{3}$. \\ Po-Wu Gean ${ }^{3,4} \cdot$ Yu-Min Kuo ${ }^{3,5}$ • Ju-Ming Wang 1,3,5,6,8
}

Received: 17 February 2015 / Accepted: 13 July 2015 / Published online: 26 July 2015

(C) The Author(s) 2015. This article is published with open access at Springerlink.com

\begin{abstract}
The progression of Alzheimer's disease (AD) has been associated with astrocytes-induced neuroinflammation. However, the detailed mechanism of astrocytes associated with learning impairments and neuronal loss in $\mathrm{AD}$ is poorly defined. Here, we provide novel evidences that astrocytic miR-135a is critical for neuronal viability and spatial learning ability in vivo. The $\mathrm{AppTg} / \mathrm{Cebpd}^{-/}$mice showed a spatial learning improvement compared with the APPswe/PS1/E9 bigenic (AppTg) mice. miR-135a was found to be a CCAAT/enhancer binding protein $\delta(\mathrm{CEBPD})$ responsive miRNA and can repress the
\end{abstract}

Electronic supplementary material The online version of this article (doi:10.1007/s12035-015-9359-z) contains supplementary material, which is available to authorized users.

Ju-Ming Wang

wwwjm4721@yahoo.com.tw

1 Institute of Bioinformatics and Biosignal Transduction, College of Bioscience and Biotechnology, National Cheng Kung University, Tainan 701, Taiwan

2 Graduate Institute of Neural Regenerative Medicine, College of Medical Science and Technology, Taipei Medical University, Taipei 110, Taiwan

3 Institute of Basic Medical Sciences, National Cheng Kung University, Tainan 701, Taiwan

4 Department of Pharmacology, National Cheng Kung University, Tainan 701, Taiwan

5 Department of Cell Biology and Anatomy, National Cheng Kung University, Tainan 701, Taiwan

6 Infectious Disease and Signaling Research Center, National Cheng Kung University, Tainan 701, Taiwan

7 Center for Neurotrauma and Neuroregeneration, Taipei Medical University, Taipei 110, Taiwan

8 Institute of Medical Sciences, College of Medicine, Taipei Medical University, Taipei 110, Taiwan transcription of thrombospondin 1 (THBS1) / Thbs1 (mouse) via its $3^{\prime}$-untranslated region ( $\left.3^{\prime} \mathrm{UTR}\right)$. We used different experimental approaches to attenuate the expression of CEBPD/ Cebpd (mouse) or miR-135a in astrocytes and found the following results: increase in THBS1/Thbs1 expression, decrease in neuronal apoptosis, and increase in growth of neurites. Importantly, injection of miR-135a antagonist (AM135a) into the brain of AppTg mice was found to prevent neuronal apoptosis and improved the spatial learning ability. Together, our findings demonstrate a critical function for the astrocytic CEBPD, and point to miR-135a antagonist as an attractive therapeutic target for the treatment of Alzheimer's disease.

Keywords miR-135a $\cdot$ Neuronal viability $\cdot$ Spatial learning ability $\cdot$ Neuroinflammation $\cdot$ Neuroprotective factor

\section{Introduction}

Neuroinflammation is a prominent feature of Alzheimer's disease (AD) and has been suggested to play a role in $\mathrm{AD}$ progression [1-3]. Current consensuses suggest that neuroinflammation can lead to neuronal dysfunction, death, and ultimately severe cognitive impairment of $\mathrm{AD}$ patient $[4,5]$. Accumulated results found that the reactive astrocytes are involved in the induction of neuroinflammation [6-8]. Astrocytes are originally thought to be supportive glial cell components in the central nervous system (CNS), which provide energy metabolites to neurons and regulate neuron maturation $[9,10]$. Recently, it has also been recognized that the secretory function of astrocytes can further regulate neuronal survival and neuronal repair after CNS injury [11]. Thrombospondin 1 (THBS1) is a multimeric extracellular matrix glycoprotein [12] secreted by astrocytes, which can function in neuronal dendritic growth, axonal sprouting, and synaptogenesis [13-15]. 
CCAAT/enhancer binding protein delta (CEBPD) is a pivotal transcription factor in brain inflammation and is a member of CCAAT/enhancer binding protein (C/EBP) family [16]. CEBPD is responsive to many proinflammatory cytokines involved in the pathogenesis of neurodegenerative diseases $[17,18,1]$ such as interleukin-1 $\beta$ (IL-1 $\beta$ ), interleukin-6 (IL6 ), and tumor necrosis factor $\alpha(\mathrm{TNF} \alpha)[19,1]$. Interestingly, the expression of CEBPD was found to be increased in ageassociated disorders including AD [20], atherosclerosis [21], type 2 diabetes [22], and RA [23]. We have previously tried to attenuate the expression of CEBPD and found that it can lead to better prognosis in mouse model of $\mathrm{AD}[24,25]$. The better $\mathrm{AD}$ prognosis has been attributed to attenuation in endothelial cell-mediated angiogenesis and macrophage-mediated phagocytosis of damaged neurons and increase in anti-apoptosis effect of astrocytes [26, 25, 27].

The role of CEBPD in the pathogenesis of AD has been investigated, but there are limited studies on the signal transduction pathway that CEBPD undertook in the pathogenesis of AD. Specifically, we were interested to investigate the downstream miRNA targets of astrocytic CEBPD and how it can lead to neuroinflammation. miRNAs are small non-coding RNA that regulate gene expression post-transcriptionally by base-pairing to mRNA [28]. There is evidence that imbalanced in the expression of miRNAs can lead to neurodegenerative diseases [29-31] and differential expression of miRNA in astrocytes and neurons after ischemic injury [32].

Glia-mediated neurotoxicity and neuroprotection have been suggested to be involved in the cognitive loss of AD patients. However, astrocytes participate in neuronal loss and consequent learning impairments in $\mathrm{AD}$ is poorly defined. Transcription factor CEBPD is significantly activated in astrocytes of AD patients and AppTg mice [20,26]. In this study, the deficit of spatial learning ability in AppTg mice was ameliorated in AppTg/Cebpd ${ }^{-1}$ mice. Therefore, the investigation of CEBPD biology in astrocytes, especially in regulation of neurotrophic factors, could provide a new insight for understanding the communication of astrocytes and neuronal cells in AD pathogenesis. Our results suggested that astrocytic CEBPD activation results in the impairment of spatial learning ability through activating miR-135a to suppress neurotropic factor THBS1. Importantly, the miR-135a antagonist (AM135a) can effectively recuse the spatial learning ability of $A p p T g$ mice.

\section{Materials and Methods}

\section{Materials}

$\alpha$-Tubulin antibody (T6199) was purchased from Sigma (St. Louis, MO, USA) and CEBPD antibody (SC-636) was purchased from Santa Cruz Biotechnology (Santa Cruz, CA, USA). NeuN antibody (MAB377) was purchased from Merck
Millipore. The cleaved caspase 3 antibody (\#9661) was purchased from Cell Signaling Technology (Danvers, MA, USA). The antibodies against THBS1 (GTX21823) and MAP2 (GTX11267) were purchased from GeneTex (Irvine, CA, USA). Secondary antibodies used in immunofluorescence analysis were goat anti-mouse/rabbit $\operatorname{IgG}(\mathrm{H}+\mathrm{L})$ secondary antibody, Alexa Fluor ${ }^{\circledR} 488$ conjugate (A-11001/A$11008)$ and goat anti-mouse/rabbit $\operatorname{IgG}(\mathrm{H}+\mathrm{L})$ secondary antibody, Alexa Fluor ${ }^{\circledR} 568$ conjugate (A-11031/A-11011) obtained from Invitrogen (Carlsbad, CA, USA). Secondary antibodies used in Western blot analysis were goat antimouse/rabbit IgG, peroxidase-conjugated (AP-124P/AP132P) purchased from Merck Millipore. TRIzol RNA extraction reagent, Dulbecco's modified Eagle's medium (DMEM), and Opti-MEM medium were obtained from Invitrogen (Carlsbad, CA, USA). All oligonucleotides were synthesized by MDBio Inc. (Taipei, Taiwan). Fetal bovine serum (FBS) was purchased from HyClone Laboratories (Logan, UT, USA).

\section{Animals}

The Cebpd-deficient mice were a gift from Dr. E. Sterneck. The APPswe/PS1/E9 transgenic (AppTg) mice were obtained from Jackson Laboratory (Bar Harbor, ME, USA, stock no. 004462). The AppTg mice were crossed with $\mathrm{Cebp}^{/-}$mice on the C57BL/6 genetic background. Female mice heterozygous for $A p p T g$ mice was intercrossed with $\mathrm{Cebp}^{/ /}$homozygous mice; the offspring $\left(A p p \mathrm{Tg}^{+/-} / \mathrm{Cebpd}^{+/-}\right)$were then bred to each other to produce the $\mathrm{App} \mathrm{Tg} / \mathrm{Cebp}^{{ }^{-1}}$ mice in this study. The 12 month aged wild-type $\left(\mathrm{Cebp}^{+/+}\right), A p p \mathrm{Tg}$, and

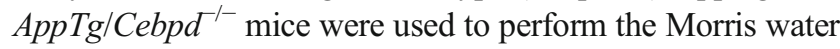
maze in this study. The $N$ number of each group is $3-5$.

\section{Cell Culture and Preparation of Primary Cells}

U373MG (human glioblastoma-astrocytoma) and SH-SY5Y (human neuroblastoma) cells were cultured in DMEM or DMEM/F12 containing $10 \%$ FBS, $100 \mu \mathrm{g} / \mathrm{mL}$ streptomycin, and 100 units $/ \mathrm{ml}$ penicillin. For the preparation of primary mouse astrocytes and cortical neuron, the cortex were removed from P0 mouse brains and dissected in HEPESbuffered saline, carefully stripped of their meninges and digested with $0.25 \%$ trypsin in Hanks' Balanced Salt Solution (Invitrogen, Carlsbad, CA, USA) for $10 \mathrm{~min}$ at $37{ }^{\circ} \mathrm{C}$. Trypsinization was stopped by adding an equal volume of culture medium. Cortical neurons were dissociated specifically by trituration in neurobasal plus B27 supplemented with $1 \%$ L-glutamine and $1 \%$ penicillin medium and passage through a $70-\mu \mathrm{m}$ nylon strainer. The solution was pelleted (10 min, $200 \mathrm{~g})$ and then resuspended in culture medium and brought to a single cell suspension by repeated pipetting followed by passage through a $70-\mu \mathrm{m}$ nylon strainer. Later, 
astrocytes were seeded on plates coated with laminin $(20 \mu \mathrm{g} /$ $\mathrm{mL}$, Invitrogen). Laminin-coating favors astroglial growth and inhibits microglial growth [33]. Cortical neurons were then plated on glass slides or plastic culture dishes coated with poly-L-lysine (Sigma).

\section{Immunofluorescence Analysis}

The frozen mouse brain sections were treated with protein blocker/antibody diluents (Bio SB) for $1 \mathrm{~h}$. In the same buffer solution, the sections were incubated overnight with primary antibodies at $4{ }^{\circ} \mathrm{C}$. These primary antibodies included caspase 3 and MAP2. For the staining of cultured cells, primary cortical neuron cells were post-fixed in $4 \%$ paraformaldehyde in phosphate-buffered saline (PBS) for $10 \mathrm{~min}$, followed by $0.5 \%$ Triton X-100 in PBS at room temperature for $10 \mathrm{~min}$. The fixed neuron cells were further incubated with primary antibodies overnight against target proteins in $3 \%$ bovine serum albumin at $4{ }^{\circ} \mathrm{C}$. Pretreated slides of the tissue sections or neuron cells were washed with $0.05 \%$ Tween-20 in PBS and then incubated with Alexa488- or 568-conjugated secondary antibodies for $1 \mathrm{~h}$ then washed again with $0.05 \%$ Tween20 in PBS. Next, the glass slides were counter-stained and mounted with ProLong Gold antifade reagent with 4', 6diamidino-2-phenylindole for immunofluorescence microscopy.

\section{The Preparation of Conditioned Medium}

For the collection of CM, wild-type and Cebpd-deficient primary astrocytes were pretreated with or without $5 \mathrm{ng} / \mathrm{mL} \mathrm{IL-}$ $1 \beta$ (Invitrogen, Carlsbad, CA, USA) for $6 \mathrm{~h}$. Later, the IL- $1 \beta$ pretreated cells were washed by PBS and replaced in the serum-free medium. After additional $12 \mathrm{~h}$, the supernatants were collected after centrifuge at $5000 \mathrm{~g}$ for conditioned media.

\section{Cell Survival Assays}

For the neuronal cell survival assay, P0 wild-type and Cebpddeficient primary cortical neurons were plated and maintained for 7 days. The experimental cells were grown in the conditioned medium as mentioned above for $48 \mathrm{~h}$. Next, the media was removed and replaced with diluted 3-(4,5cimethylthiazol-2-yl)-2,5-diphenyl tetrazolium bromide (MTT) reagent for $4 \mathrm{~h}$. The samples were then measured spectrophotometrically at $595 \mathrm{~nm}$ using an enzyme-linked immunosorbent assay plate reader.

\section{Microarray Analysis}

Total RNAs were isolated using the TRIzol RNA extraction reagent. Samples were validated with Agilent Human and
Primate miRNA one array (Phalanx Biotech., Taipei, Taiwan), following the manufacturers' protocols. All processes were performed by Phalanx Biotech Company (Taipei, Taiwan). Good quality signals were obtained by filtering for scores of $p$ value $<0.05$ in all replicates, $M$ value of $>6$ in all signals, and more than 1.5 -fold change.

\section{RNA Isolation, Reverse Transcription, and Quantitative Real-Time PCR}

Total RNAs were isolated using the TRIzol RNA extraction reagent and subjected to reverse transcription with SuperScriptTM III. Specific primers used for the RT-PCR analysis are as follows: for GAPDH (20 cycles and product size: 576 b p ), 5'C CATCACCATC T TCCAGGAG-3' and $5^{\prime}$ CCTGCTTCACCACCTTCTTG-3'; for THBS1 (28 cycles a nd product size: 376 b p ), $5^{\prime}$ GCTCAGA T TGATGTTATGG-3' and 5' GGGAATACTTCTCTGCAGAG-3'; for Thbs 1 (28 cycles a n d product size: 192 b p ), $5^{\prime}$ CCAA A GCCTGCAAGAAAGAC-3' and 5'CCTGCTTGTTGCAAACTTGA-3'; for CEBPD (26 cycles and product size: 267 bp), $5^{\prime}$ AGCGCA A CA A A TCGCCGTG-3' and 5'GTCGGGTCTGAGGTATGGGTC-3'; and for Cebpd (26 cycles and product size: 429 bp), 5'A T C GCT GCA GC T T C C TATGT- ${ }^{\prime}$ and $5^{\prime}$ GGTTAAGCCCGCAAACATTA-3' The PCR products were separated by electrophoresis in $1 \%$ agarose gels and visualized with ethidium bromide staining. For qRTPCR, the resultant cDNA was mixed with SYBR Premix ExTaq kit and appropriate primers, and quantitative PCR was performed with Thermocycler C1000 (BioRad, Hercules, CA, USA). Forty cycles were set for qRT-PCR program and the abundances of interested gene expression were calculated following the formula $\left(2^{-\Delta \Delta C t}\right)$ suggested in the instruction of qRT-PCR kit (Applied Biosystems). Specific primers used for the qRT-PCR analysis are as follows: for $G A P D H, 5^{\prime}-$ C C A C C A G A G A T T TGGAT-3' and 5'AAGGTCATCCCTGAGCTGAA-3'; for THBS1, 5'GACCTGCCACAT TCAGGAGT-3' and 5'CTTTCTTGCAGGCTTTGGTC-3'; for Thbs 1, 5'CCAAAGCCTGCAAGAAAGAC-3' and 5'CCTGCTTGTTGCAAACTTGA-3'; for miR-135a reverse transcription (RT) primer, 5' CTCAACTGGTGTCGTGGAGTCGGCAATCACTTGAGTCACATAG-3'; and for miR-135a forward, 5'A C A C T C C A G C T C A G T A T G G C T T T T T A T T C C TA T T - 3' and reverse, $5^{\prime}$ CTCAACTGGTGTCGTGGAGTCGGCAATTCAG-3'. 


\section{TaqMan Reverse Transcription-PCR for miRNA Quantification}

Total RNA was isolated using TRIzol according to the manufacturer's protocol, reverse-transcribed using a TaqMan ${ }^{\circledR}$ microRNA reverse transcription kit, and subjected to realtime PCR using a TaqMan ${ }^{\circledR}$ microRNA assay kit (Applied Biosystems).

\section{Cloning and Mutagenesis}

The 3'-UTRs of THBS1 and Thbsl genes and 5'flanking region of GLYCTK-AS1-001 gene (host gene of intronic miR-135a) were cloned from U373MG cells by using the DNeasy Tissue Kit (QIAGEN, Düsseldorf, Germany) and PCR. The following primers were used for PCR and cloning: GLYCTK-AS1-001 forward, 5'KpnI-CGGGGTAC CCCGAGCCCCCTGCAACCT-3' a $\mathrm{nd} \mathrm{r}$ e vers e p r i m e r $5^{\prime} \mathrm{X}$ h o 1 CCGCTCGAGCGGACCGAGAGATAAAGCCTG-3'; T H B S 1-3'U T R forward, 5'X b a l I TCTAGATGTAGCTTGTGCAGATGT-3' and reverse, 5' EcoRV-CTGAGATATCTATTCCAATGGCAATGAG-3'; Thbs1-3'UTR (1w) forward, 5'Xbal1-TCTAGA GCCAATCATAACCAGC-3' and reverse, 5'EcoRVGATATCGTATAGAAGTTCCACCTTTGT-3'. These PCR fragments were subcloned into pGL3-promoter or pGL3-basic vector for further reporter assay. Mutant reporter plasmids were constructed by the site-directed mutagenesis following the instructions of the QuikChang Site-directed Mutagenesis Kit (Stratagene, CA, USA) with the primers of THBS1-3'UTR mutant, $5^{\prime}$ - A A A T T G C A A A G A A A G A T A T C A G G T C T T C A ATA C T GT - 3', M 1, $55^{\prime}$ CTCCTTGTAATGGATATCAGGAGTACTCTA-3', or M2, 5'-GTTTGCTTTTGGGATATCCAAAGCGCCTAT-3'.

\section{DNA Vector Transfection and Reporter Assay}

The cells were transfected by TurboFect Transfection Reagent (Thermo Scientific, Pittsburgh, PA, USA) according to the manufacturer's instructions. The total amount of DNA for each experiment was matched to equal with their individual backbone vector. After transfection, the lysates of experimental cells were harvested for luciferase assay system following the manufacturer's instructions (Promega, Madison, WI, USA). The $50 \mu \mathrm{L}$ of cell lysate, $50 \mu \mathrm{L}$ of luciferin, and $180 \mu \mathrm{L}$ of luciferase assay reagent were injected into a luminometer tube. After votexing, the tube was placed in the luminometer and luciferase activity measured.

\section{Pre-miR-135a and Antisense of miR-135a (A-135a) -Inducible Stable Cells}

The primers for PCR using pre-miR-135a forward (5'-AgeIAGGCCTCGCTGTTCTCTATGGC-3') and pre-miR-135a reverse (5'-PmeI-TGTCCCCGCCGTGCG-3') to generate pre-miR-135a construction in pAS4w.1.Pneo, a tetracyclineinducible system of lentiviral expression vector. The A-135a construction in pLAS1w.3xLacO, a lentiviral expression vector, used the DNA fragment as follows: 5' TATGGCTTTTTATTCCTATGTGACTCGAGTCACATAGGAATAAAAAGCCATATTTTT-3'. Stable U373MG cells containing Pre-miR-135a and A-135a were generated by pLAS.AS3w.aOn.Pbsd lentiviral infectants and parental U373MG cells, respectively. Doxycycline $(2 \mu \mathrm{g} / \mathrm{mL})$ was used to induce miR-135a expression. IPTG $(500 \mu \mathrm{M})$ was used to induce A-135a expression. The lentiviral expression vectors were obtained from the National RNAi Core Facility located at the Genomic Research Center of Institute of Molecular Biology, Academia Sinica (Taiwan).

\section{Western Blot Analysis}

For Western analysis, cells were lysed with modified RIPA buffer [50 mM Tris- $\mathrm{HCl}$ (pH 7.4), $150 \mathrm{mM} \mathrm{NaCl}, 1 \mathrm{mM}$ EDTA, $1 \%$ Nonidet P-40, $0.25 \%$ sodium deoxycholate, $1 \mathrm{mM}$ PMSF, aprotinin $1 \mu \mathrm{g} / \mathrm{mL}$, and leupeptin $1 \mu \mathrm{g} / \mathrm{mL}]$. Lysates were resolved on a sodium dodecyl sulfate (SDS)containing $10 \%$ polyacrylamide gel, transferred to polyvinylidene difluoride (PVDF) nylon membrane and probed with anti-THBS1(1:1000), anti-CEBPD (1:2000), anti- $\alpha$ tubulin $(1: 10,000)$ at $4{ }^{\circ} \mathrm{C}$ overnight. Specific bands were detected by a horseradish peroxidase-conjugated antibody specific for either rabbit or mouse IgG (1:3000) and revealed by an enhanced chemiluminescence (ECL) Western blot system from Pierce (Rockford, IL, USA).

\section{Lentiviral Knockdown Assay}

Virus was produced from Phoenix cells by co-transfection of the various shRNA expression vectors in combination with pMD2.G and psPAX2. After determining the viral infection efficiency, 10 M.O.I. of lentivirus containing $\operatorname{sh} \beta$ galactosidase (shLacZ) or shCEBPD were used to infect U373MG cells for $48 \mathrm{~h}$. In all lentiviral experiments, medium containing uninfected viruses was removed before conducting further assays. The shRNA sequences in lentiviral expression vectors shown as follows: shLacZ, 5' CCGGTGTTCGCATTATCCGAACCATCTCGAGATGGTTCGGATAATGCGAACATTTTTG-3' and shCEBPD, 5'CCGGGCCGACCTCTTCAACAGCAATCTCGAGATTGCTGTTGAAGAGGTCGGCTTTTT-3'. The lentiviral knockdown expression vectors were obtained from the 
National RNAi Core Facility located at the Genomic Research Center of Institute of Molecular Biology, Academia Sinica (Taiwan).

\section{Chromatin Immunoprecipitation Assay}

The chromatin immunoprecipitation (ChIP) assay was carried out essentially as described by Wang et al. [34]. Briefly, U373MG cells were treated with $1 \%$ formaldehyde for $15 \mathrm{~min}$. The cross-linked chromatin was then prepared and sonicated to an average size of $500 \mathrm{bp}$. The fragmented gDNA-protein complex was immunoprecipitated with antibodies specific for CEBPD or control rabbit immunoglobulin $\mathrm{G}$ at $4{ }^{\circ} \mathrm{C}$ overnight. After reversal of the cross-linking, the immunoprecipitated chromatin was amplified by primers related to the specific regions of the target genes genomic locus. The primers are as follows: FR-211 forward, 5'TCCTCTACTGGCCCTTTAGTCCCTG-3' and FR-211 reverse, 5'-AGCTGGTTCTCAGCTGAAACAAAGA-3'; FR250 forward, 5'-AGAGACAGAGACAGATAGGA A GCA A - 3' and FR - 250 reverse, 5' ACAGAAAAGTTGCCAGAATAGTGAT-3'. The amplified DNA products were resolved by agarose gel electrophoresis.

\section{In Situ Hybridization}

Non-radioactive in situ hybridization was performed on $10 \mu \mathrm{m}$ sections from mouse brain tissue blocks using the digoxigenin-labeled locked nucleic acid-modified detection probe $(20 \mu \mathrm{M}$; 5'-TCACATAGGAATAAAAAGCCATA-3'; Exiqon, Tustin, CA) complementary to mature miR-135a and IsHyb in situ hybridization kit (BioChain, Hayward, CA) following the protocol from Exiqon. Briefly, $10 \mu \mathrm{m} \mathrm{sec}-$ tions were deparaffinized, hydrated, and treated with proteinase $\mathrm{K}\left(10 \mu \mathrm{g} / \mathrm{mL}\right.$; QIAGEN) at $37^{\circ} \mathrm{C}$ for $15 \mathrm{~min}$ and fixed with $4 \%$ paraformaldehyde for $20 \mathrm{~min}$. The sections were incubated in pre-hybridization solution at $50{ }^{\circ} \mathrm{C}$ for $3 \mathrm{~h}$ and then in hybridization solution with digoxigenin-labeled, locked nucleic acid-modified miR-135a probe at $50{ }^{\circ} \mathrm{C}$ for $16 \mathrm{~h}$. The sections were incubated in the phosphatebuffered saline diluted anti-digoxigenin-AP antibody (1:100) at room temperature for $1 \mathrm{~h}$, washed with $2 \times$ standard saline citrate (SSC), $1.5 \times \mathrm{SSC}, 0.2 \times \mathrm{SSC}$, incubated in blocking solution for $1 \mathrm{~h}$ at room temperature, washed with phosphate-buffered saline three times, then washed with $1 \times$ alkaline phosphatase buffer twice. The NBT/BCIP solution was used for visualization of hybridization signal.

\section{Treatment of AppTg Mice with Antagomirs}

Mice were anesthetized by intraperitoneal injection of chloral hydrat $(4 \mathrm{mg} / \mathrm{kg})$ and then positioned in a stereotaxic apparatus. Using a 30-guage Hamilton syringe, $1 \mu \mathrm{L}$ of phosphate-buffered saline containing $0.5 \mathrm{nmol}$ of the antagomir Cy3-labeled AM135a or a scrambled antagomir (RiboBio ,Guangzhou, China) was injected over $5 \mathrm{~min}$ into the third ventricle at the following coordinates: antero-posterior, $-1.06 \mathrm{~mm}$; medio-lateral, $0.00 \mathrm{~mm}$; and dorso-ventral, $-2.4 \mathrm{~mm}$ from the bregma. The needle was left in place for another $10 \mathrm{~min}$ and then gently removed.

\section{Morris Water Maze Test}

The training apparatus was a circular white pool $(120 \mathrm{~cm}$ in diameter) containing water at $24{ }^{\circ} \mathrm{C}$. A platform (10 $\mathrm{cm}$ in diameter) was submerged $1 \mathrm{~cm}$ under the water surface. Before the test, mice were first trained to swim and climb on to the platform. For the hidden platform trial, four sessions were performed (four trials per session per day were carried out). Mice were allowed to search for the platform for $120 \mathrm{~s}$. If the mice did not find the platform within $120 \mathrm{~s}$, they were gently guided to it. All mice were allowed to remain on the platform for $20 \mathrm{~s}$. The time spent to reach the hidden platform was recorded.

\section{Results}

\section{Role of Astrocytic CEBPD in Neuron Apoptosis and Spatial Learning in AppTg Mice}

To find out whether the expression of Cebpd has direct involvement in the spatial learning ability of mice, Morris water maze was conducted using wild-type $\left(\mathrm{Cebp}^{+/ t}\right), A p p T g$, and AppTg/Cebpd $d^{--}$mice. As expected, AppTg mice have impaired spatial ability and failed to show improvement in latency to hidden even on day 4 (Fig. 1a). Interestingly, AppTg/ $\mathrm{Cebpd}{ }^{--}$mice showed a time-dependent improvement in their ability to navigate through the water maze. However, $\mathrm{AppTg} / \mathrm{Cebpd}^{-1-}$ mice's improvement in latency to hidden was not as pronounced as wild-type mice. To find out whether neuron viability has a role in $\mathrm{AppTg} / \mathrm{Cebpd}^{--}$mice's improvement in latency to hidden, we compared the staining of caspase 3 in AppTg and AppTg/Cebpd $d^{/-}$mice. As compared to AppTg mice, the staining of caspase 3 was greatly attenuated in $\mathrm{AppTg} / \mathrm{Cebpd}^{-1}$ mice (Fig. 1b). To quantitatively determine if Cebpd has a role in inflammationdependent cell viability, MTT assay was conducted in primary $\mathrm{Cebp}^{\mathrm{T}^{-}}$neurons treated with IL-1 $\beta$. To our surprise, the primary $\mathrm{Cebpd}^{--}$neurons did not enhance their cell viability as compared to primary $\mathrm{Cebpd}^{+/+}$ neurons, upon IL-1 $\beta$ treatment (Fig. 1c). Thus, we tested whether astrocytic CEBPD was responsible for the 


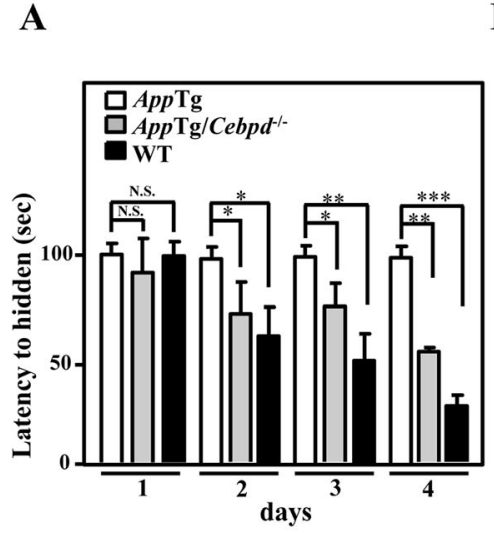

B
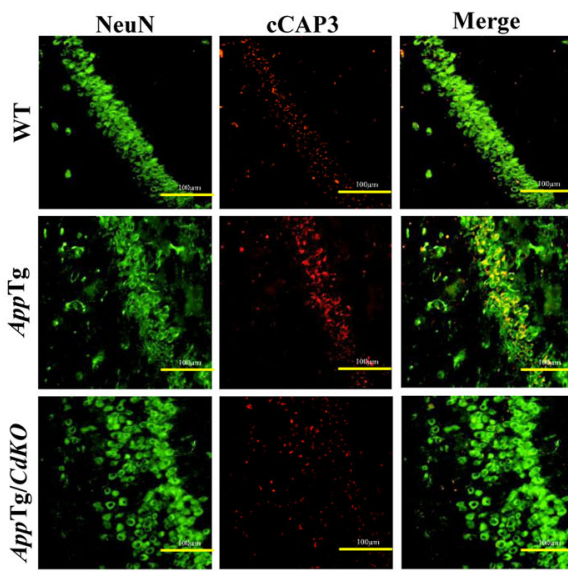

Merge

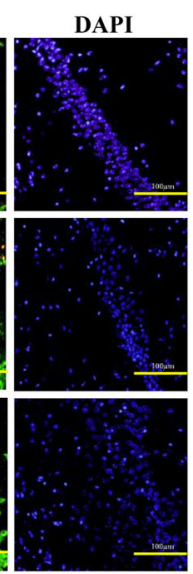

C

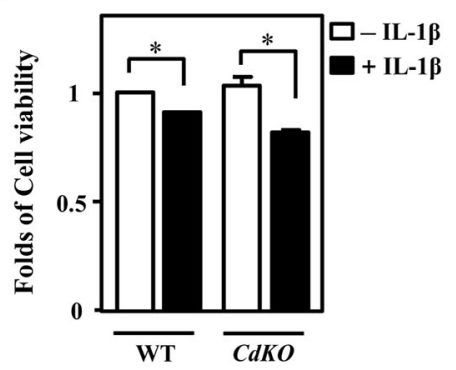

D

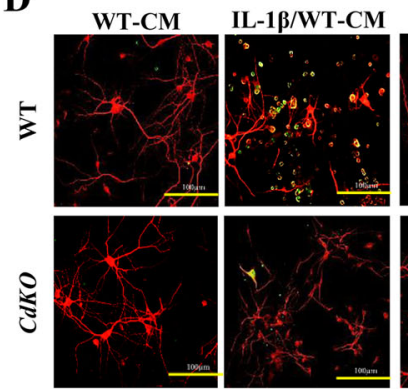

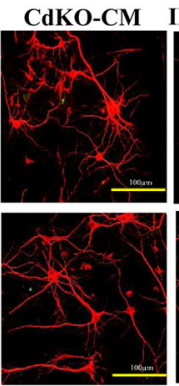

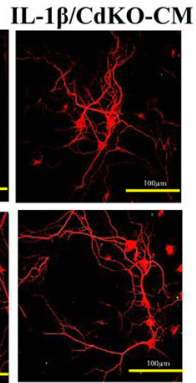

Fig. 1 Neuronal apoptosis and spatial learning ability in $\mathrm{AppTg} / \mathrm{Cebpd}^{\prime}$ mice. a Spatial learning ability of wild-type (WT; C57BL/6), AppTg, and $A p p \operatorname{Tg} / \mathrm{Cebpd}^{-1}$ mice. Time required by WT ( $\left.n=5\right), \operatorname{App} \mathrm{Tg}(n=5)$, and $\mathrm{App} \mathrm{Tg} / \mathrm{Cebpd}^{-1-}(n=3)$ mice to reach the hidden platform (latency to hidden) was analyzed in the Morris water maze. b The apoptosis of neurons was attenuated in $\mathrm{AppTg} / \mathrm{Cebpd}^{/-}$mice. The brain tissues were subjected to immunofluorescence staining with the antibody recognized NeuN or cleaved caspase 3 (cCap3; active caspase 3). Scale bar= $100 \mu \mathrm{m}$. c Primary $\mathrm{Cebpd}^{-1}$ neurons have no effect to reverse IL-1 $\beta$ induced cell death. The MTT assay was conducted as indicated. (d) Attenuated Cebpd expression in primary astrocytes does not contribute to neuronal death. The conditioned medium came from either IL- $1 \beta$ pretreated primary WT or $\mathrm{Cebpd}^{{ }^{-1}}$ astrocytes. Primary cortical neurons in WT and $\mathrm{Cebpd}^{-1}$ mice were seeded and grown on coverslips with the mixture medium (9:1) of neuronal maintenance medium and above conditioned medium for $72 \mathrm{~h}$. The experimental neurons were performed with immunofluorescence staining by anti-MAP2 antibodies for morphological examination and anti-cleaved caspase 3 (cCap3) antibodies for cell death detection. Scale bar $=100 \mu \mathrm{m}$. Data represent two independent experiments with three mice/group in B or three independent experiments in $\mathbf{c}$ and $\mathbf{d}$. Data are expressed as mean \pm SEM by a Student's $t$ test. $\left({ }^{*} P<0.05 ; * * P<0.01 ; * * * P<0.001 ; N S\right.$ not significant $)$ viability of neuron instead. To address this issue, conditioned media of IL-1 $\beta$-pretreated primary wild-type or $\mathrm{Cebpd}^{/-}$astrocytes were incubated with primary neuron cells. The survival and neurite outgrowth of neurons showed little difference between Cebpd ${ }^{-1}$ and wildtype neurons, if IL-1 $\beta$ pretreated CM from wild-type astrocytes were used. However, upon incubation of the CM from IL-1 $\beta$-pretreated primary Cebpd $d^{--}$astrocytes, the survival and neurite outgrowth of $\mathrm{Cebpd}^{{ }^{--}}$neurons were attenuated (Figs. 1d and S1).

\section{CEBPD Represses THBS1 Transcription in Astrocytes}

Astrocyte-secreting neurotrophic factors are essential for neuronal survival and synaptic plasticity. Our global profiling assay showed that THBS1, a neurotrophic factor, was repressed in U373MG cells expressing CEBPD (Table 1). The possibility that CEBPD can directly repress the expression of THBS1 in U373MG cells was tested by transfection with the zinc-inducible CEBPD expression vector. RT-PCR and Western blot studies found that overexpression of CEBPD lead to decrease in expression of THBS1 (Fig. 2a). Thus, we looked at whether IL-1 $\beta$ treatment has an effect on THBS1 expression. Consistently, it was found that IL$1 \beta$ induced expression of CEBPD, leading to decrease in THBS1 expression (Fig. 2b). To find out whether CEBPD depletion can lead to an opposite effect as compare to CEBPD overexpression, IL- $1 \beta$-treated U373MG cells were infected with two different shRNA against CEBPD. It was found that knock down of CEBPD can lead to increase in THBS1 expression instead (Fig. 2c). Finally, the THBS1 repressive effect of CEBPD was examined in mouse primary astrocytes 
Table 1 Genes in response to CEBPD induction and CEBPD responsive miRNAs in U373MG cells

\begin{tabular}{|c|c|c|c|c|c|c|c|}
\hline $\begin{array}{l}\text { Upregulated } \\
\text { miRNAs }\end{array}$ & $\begin{array}{l}\text { Folds of } \\
\text { change }\end{array}$ & $\begin{array}{l}\text { Downregulated } \\
\text { mRNAs }\end{array}$ & $\begin{array}{l}\text { Folds of } \\
\text { change }\end{array}$ & $\begin{array}{l}\text { Downregulated } \\
\text { miRNA }\end{array}$ & $\begin{array}{l}\text { Folds of } \\
\text { change }\end{array}$ & $\begin{array}{l}\text { Upregulated } \\
\text { mRNA }\end{array}$ & $\begin{array}{l}\text { Folds of } \\
\text { change }\end{array}$ \\
\hline \multirow[t]{2}{*}{ hsa-mir-135a } & 1.6 & THBS1 & 0.57 & hsa-miR-30c & 0.59 & ME1 & 1.64 \\
\hline & & SERPINC1 & 0.1 & hsa-miR-24 & 0.62 & ADAMTS 5 & 1.54 \\
\hline hsa-mir-1254 & 1.6 & ETV7 & 0.55 & & & BCL2L11 & 1.54 \\
\hline \multirow[t]{4}{*}{ hsa-mir-1321 } & 1.7 & $\mathrm{BAX}$ & 0.65 & & & PDGFRA & 1.51 \\
\hline & & BCL2L1 & 0.62 & hsa-miR-17 & 0.64 & ETV1 & 1.53 \\
\hline & & SYK & 0.6 & hsa-miR-320 & 0.64 & ETV1 & 1.53 \\
\hline & & DTX1 & 0.65 & & & KITLG & 1.85 \\
\hline \multirow[t]{23}{*}{ hsa-mir-198 } & 1.74 & DTX & 0.65 & hsa-miR-320b & 0.64 & ETV1 & 1.53 \\
\hline & & & & & & KITLG & 1.85 \\
\hline & & & & hsa-miR-320c & 0.64 & ETV1 & 1.53 \\
\hline & & & & & & KITLG & 1.85 \\
\hline & & & & hsa-miR-16 & 0.65 & ADAMTS5 & \\
\hline & & & & & & ITGA2 & 1.68 \\
\hline & & & & hsa-miR-29b & 0.65 & $\mathrm{BMF}$ & 1.51 \\
\hline & & & & & & PTX3 & 1.86 \\
\hline & & & & hsa-miR-15b & 0.66 & ADAMTS5 & 1.54 \\
\hline & & & & & & ITGA2 & 1.68 \\
\hline & & & & hsa-miR-181b & 0.68 & ADAMTS5 & 1.54 \\
\hline & & & & & & KITLG & 1.85 \\
\hline & & & & & & PDGFRA & 1.51 \\
\hline & & & & & & PRLR & 1.98 \\
\hline & & & & hsa-miR-19b & 0.68 & ABCA1 & 1.89 \\
\hline & & & & & & ID2 & 1.51 \\
\hline & & & & hsa-miR-23a & 0.68 & CA2 & 1.92 \\
\hline & & & & & & SLC1A1 & 1.56 \\
\hline & & & & & & TNFAIP6 & 1.65 \\
\hline & & & & hsa-miR-29a & 0.68 & $\mathrm{BMF}$ & 1.51 \\
\hline & & & & & & РTX3 & 1.86 \\
\hline & & & & hsa-miR-29a & 0.69 & RGS2 & 1.91 \\
\hline & & & & hsa-miR-29a & 0.69 & RHOU & 1.61 \\
\hline
\end{tabular}

(Fig. 2d). Treatment of mouse primary astrocytes with either TNF $\alpha$ or IL- $1 \beta$ can both lead to increase expression of CEBPD and a decrease in expression of THBS1. Interestingly in $\mathrm{Cebpd}^{-1}$ primary astrocytes, it was observed that there is a constantly high expression of Thbs1.

\section{CEBPD Activates miR-135a Transcription}

To explore which miRNAs are regulated by CEBPD in astrocytes, we conducted a microarray profiling to identify the CEBPD-regulated miRNAs (Table 2). Interestingly, miR-135a, a putative THBS1 mRNA binding suppressor, was observed to be upregulated by CEBPD in the global profiling of miRNA. To find out if CEBPD expression has direct correlation with miR-135a expression, we investigated the expression of miR-135a in U373MG cells either by overexpression of CEBPD or knock down of CEBPD. We obtained a consistent result in which the overexpression of CEBPD results in increasing expression of miR135a (Fig. 3a), while knock down of CEBPD results in reduce expression of miR-135a upon IL-1 $\beta$ stimulation (Fig. 3b). Subsequently, we explored whether CEBPD still regulate miR-135a in primary astrocytes. It was observed that the expression of miR-135a still increased upon IL-1 $\beta$ treatment in primary Cebpd $d^{+/}$ but not in $\mathrm{Cebpd}^{-1}$ astrocytes (Fig. 3c). Next, we wished to find out how CEBPD can increase the expression of miR-135a. Since miR-135a is located at intron 1 of GLYCTK-AS1-001 gene, we first made sure 
A

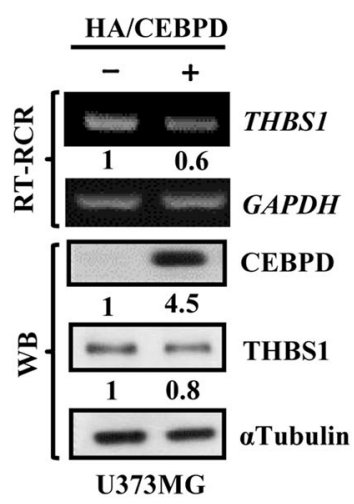

B

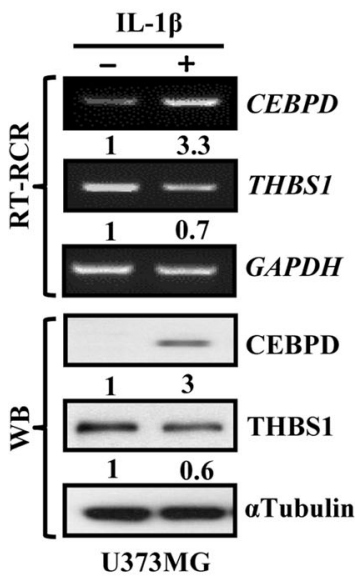

C

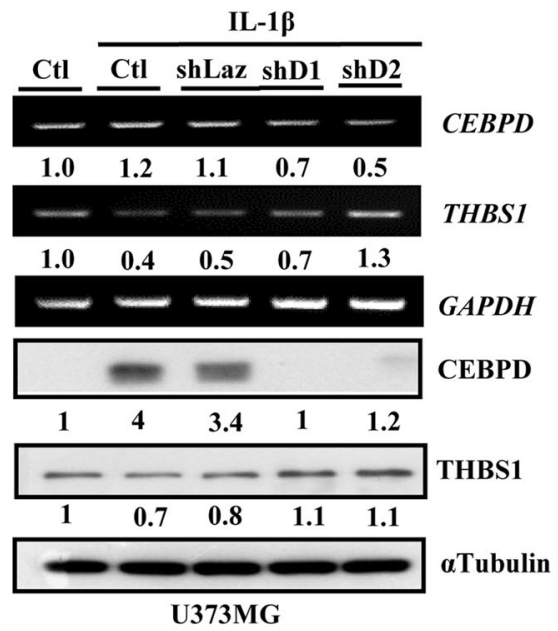

D

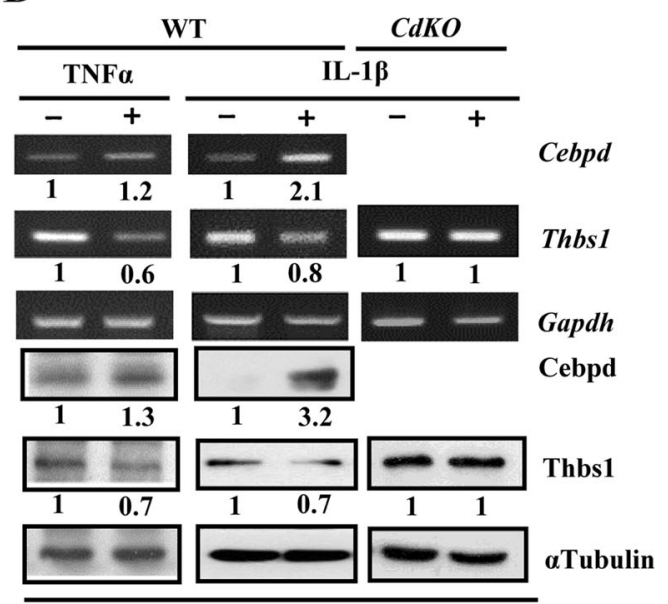

Primary astrocytes

THBS1 transcription. U373MG cells were infected with lentivirus of sh-galactosidase (shLacZ) or shCEBPD (shD1, shD2) and then treated with IL-1 $\beta$ for $3 \mathrm{~h}$. Total RNA or cell lysates were harvested for RT-PCR or Western blot analysis. $\mathbf{d}$ Loss of CEBPD in primary astrocytes reverses IL-1 $\beta$-attenuated Thbs 1 expression. Primary Cebpd $d^{+/+}$(WT) and $\mathrm{Cebpd}^{-/}(\mathrm{CdKO})$ astrocytes were treated with $20 \mathrm{ng} / \mathrm{mL} \mathrm{TNF} \alpha$, or $5 \mathrm{ng} / \mathrm{mL} \mathrm{IL-1 \beta}$ for $3 \mathrm{~h}$, then the RT-PCR and Western blot were performed to examine the expression of Thbs 1 mRNA and protein, respectively

miR-135a Can Target to THBS1 (Human)/Thbs1 (Mouse) 3'UTR and Contributes to the Repression of THBS1/ Thbs1

To verify that miR-135a can indeed repress the expression of THBS1, we infected a DOX-inducible miR-135a expression system into primary astrocytes (Fig. 4a) and U373MG cells (Fig. 4d). In both studies, we found that increase expression of miR-135a attenuates the level of THBS1. Our recent study demonstrated that prostaglandin 2 (PGE2) could repress THBS1 3'UTR reporter activity through a miR-135a binding motif. Two miR-135a binding motifs were identified in Thbs 1 
Table 2 CEBPD responsive miRNAs in U373MG cells

\begin{tabular}{|c|c|c|c|}
\hline Upregulated & Fold of change & Downregulated & Fold of change \\
\hline hsa-miR-4314 & 2.2 & hsa-miR-22 & 0.7 \\
\hline hsa-miR-788 & 1.9 & hsa-miR-1979 & 0.7 \\
\hline hsa-miR-557 & 1.8 & hsa-miR-200b & 0.7 \\
\hline hsa-miR-198 & 1.7 & hsa-miR-26b & 0.7 \\
\hline hsa-miR-2116 & 1.7 & hsa-miR-181b & 0.7 \\
\hline hsa-miR-1321 & 1.7 & hsa-miR-29a & 0.7 \\
\hline hsa-miR1193 & 1.7 & hsa-miR-138 & 0.7 \\
\hline hsa-miR-4299 & 1.7 & hsa-miR-23a & 0.7 \\
\hline hsa-miR-3131 & 1.6 & hsa-miR-19b & 0.7 \\
\hline hsa-miR-3190 & 1.6 & hsa-miR-423 & 0.7 \\
\hline hsa-miR-4300 & 1.6 & hsa-miR-515 & 0.7 \\
\hline hsa-miR-135a & 1.6 & hsa-miR-128 & 0.7 \\
\hline hsa-miR1254 & 1.6 & hsa-let-7c & 0.7 \\
\hline hsa-miR-514b & 1.6 & hsa-miR-1975 & 0.7 \\
\hline hsa-miR-1909 & 1.6 & hsa-miR-708 & 0.7 \\
\hline hsa-miR-921 & 1.6 & hsa-miR-15b & 0.7 \\
\hline hsa-miR-3144 & 1.6 & hsa-miR-103 & 0.7 \\
\hline hsa-miR-3125 & 1.5 & hsa-miR-720 & 0.7 \\
\hline hsa-miR-1914 & 1.5 & hsa-miR-16 & 0.7 \\
\hline hsa-miR-4257 & 1.5 & hsa-miR-29b & 0.7 \\
\hline \multirow[t]{13}{*}{ hsa-miR-4270 } & 1.5 & hsa-miR-1201 & 0.7 \\
\hline & & hsa-miR-320c & 0.6 \\
\hline & & hsa-miR-17 & 0.6 \\
\hline & & hsa-miR-320a & 0.6 \\
\hline & & hsa-miR-320b & 0.6 \\
\hline & & hsa-miR-21 & 0.6 \\
\hline & & hsa-miR-9 & 0.6 \\
\hline & & hsa-miR-196a & 0.6 \\
\hline & & hsa-miR-24 & 0.6 \\
\hline & & hsa-miR-107 & 0.6 \\
\hline & & hsa-miR-1248 & 0.6 \\
\hline & & hsa-miR-30c & 0.6 \\
\hline & & hsa-miR-455 & 0.6 \\
\hline
\end{tabular}

3'UTR. To confirm that Thbs $13^{\prime}$ UTR is indeed targeted by miR-135a, we constructed luciferase reporter plasmids that contained native or mutated seed sequences of Thbs $13^{\prime}$ UTR. The reporter assay were conducted by co-transfecting various mouse Thbs1 3'UTR reporters with miR-135a expression vector. We found that miR-135a repressed the native Thbs 1 3'UTR reporter activities, but these effects were lost in construct with individual mutations of miR-135a binding motifs (Fig. 4b). Similar results were also obtained from co-transfecting various THBS1 3'UTR reporters with CEBPD, pre-miR-135a expression vectors, or IL-1 $\beta$ stimulation (Fig. 4d). Next, we investigated whether inhibition of miR-135a can lead to the opposite effect of increasing THBS1 expression. We found that expression of antisense of miR-135a (A-135a) in primary astrocytes (Fig. 4c) or miR-135a antagomir (AM135a) in U373MG cells (Fig. 4f) can lead to increase THBS1 expression. Interestingly, a dose-dependent increased in expression of CEBPD was also found upon AM135a expression in U373MG cells.

\section{Attenuated CEBPD and miR-135a in Astrocytes Restores the Neuronal Neurite Outgrowth}

It has been found that the growth of neurite decrease during inflammation. We wished to determine whether knock out of CEBPD in astrocyte could still lead to growth of primary neurons upon IL-1 $\beta$ treatment. Conditioned medium from primary $\mathrm{Cebpd}^{+/+}$or $\mathrm{Cebpd}^{-/}$astrocytes with or without IL-1 $\beta$ treatment was added to primary neurons for $48 \mathrm{~h}$. It was found that neurons showed a reduction in length upon incubation with $\mathrm{CM}$ containing $\mathrm{Cebpd}^{+/+}$astrocytes with IL$1 \beta$ treatment, but there were no changes in length of primary neurons upon incubation with CM containing $\mathrm{Cebpd}^{{ }^{/-}}$astrocytes with IL-1 $\beta$ treatment (Fig. 5a). Consistently, we also found that there is reduction in the length of neurons when incubated with CM containing either U373MG cells overexpressing either CEBPD or miR-135a (Fig. S3a, S3b). There is also no change in the length of primary neurons upon incubation with $\mathrm{CM}$ containing either astrocytes (Fig. 5b) or U373MG cells (Fig. S3c) expressing antisense of miR-135a (A-135a).

\section{Intracerebral Injection of miR-135a Neutralizing Antagomir Decreases Neuronal Apoptosis and Enhances Spatial Learning Ability in AppTg Mice}

We wished to determine whether AM135a could be used as a therapeutic agent on AppTg mice. First, we investigated the expression of miR-135a in mouse brain by in situ hybridization. Enhanced expression of miR-135a was found in the brain of a 12-month-old AppTg mice but not in $\mathrm{AppTg} / \mathrm{Cebpd}^{{ }^{-}}$ mice (Figs. 6a and S4). This result prompted us to inject a Cy3-labeled AM135a (Cy3-AM135a) into the third ventricle of the 12-month-old AppTg mice. We found that Cy3AM135a was distributed throughout the hippocampus and surrounding tissue after $24 \mathrm{~h}$ (Fig. 6b). Consistent with our previous studies, the whole brain level of Thbs1 showed increased in expression at 1 week after the intraventricular injection of $0.5 \mathrm{nmol}$ AM135a (Fig. 6c). Next, we measured the effect of AM135a on preventing neuronal apotoposis. It was found that in brain section from $A p p T g$ mice injected with AM135a, activated caspase 3 expression was attenuated and co-localized with NeuN-positive markers (Fig. 6e). The 
A

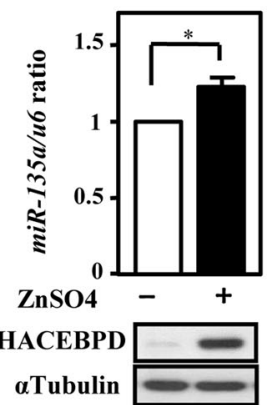

D

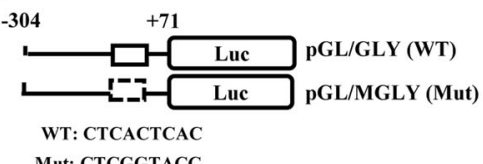

Mut: CTCGGTACC

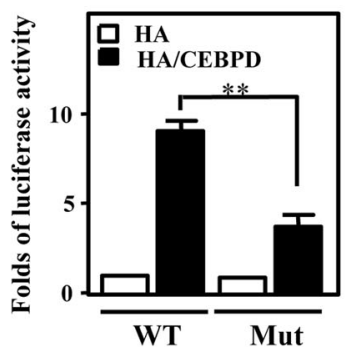

Fig. 3 miR-135a is a CEBPD responsive miRNA. a CEBPD induces miR-135a expression. qRT-PCR and Western blot confirmed that miR$135 \mathrm{a}$ levels and the expression of HA-tagged CEBPD protein from stable U373MG cells with pMT-CEBPD expression vector, respectively. b CEBPD participate in IL- $1 \beta$-induced miR-135a expression. qRT-PCR was performed with total RNA harvested from IL-1 $\beta$-treated U373MG cells with or without attenuation of CEBPD. $\mathbf{c}$ miR-135a expression is unaltered in primary $\mathrm{Cebp}^{/-}$astrocytes. qRT-PCR was performed using total RNA harvested from primary $\mathrm{Cebpd}^{+/+}$and $\mathrm{Cebpd}^{-/}$astrocytes with or without IL-1 $\beta$ treatment. d CEBPD increases miR-135a promoter activities. Schematic representation of reporter constructs with the GLYCTK-AS1-001 promoter. The approximate location of putative CEBPD-binding motif was indicated by open box. A luciferase activity

caspase activity of brain lysates from $A p p T g$ mice injected with AM135a were also attenuated (Fig. S5). Finally, we carried out Morris Water Maze test on AppTg mice treated with AM135a. The escape latency of $A p p T g$ mice treated with AM135a was significantly decreased after day 3 when it was compared with mice treated with scrambled antagomir (Fig. 6d).

\section{Discussion}

$\mathrm{AD}$ is a common neurodegenerative disease, which is associated with neuronal loss and severe cognitive deficit. Most studies about $\mathrm{AD}$ have focused on neuronal dysfunction, but few have concentrated on astrocytes' role in pathogenesis of AD. In AD patients and AppTg mice, CEBPD and Cebpd, respectively, are found to be highly expressed in astrocytes
C

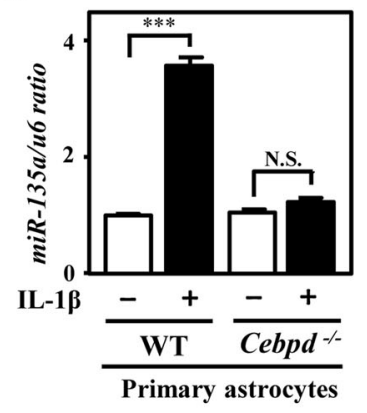

$\mathbf{E}$
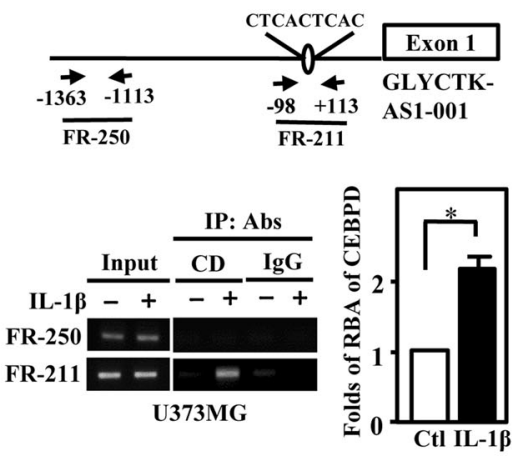

was conducted by co-transfected reporter and expression vectors as indicated in U373MG cells. e CEBPD can directly bind to the GLYCTKAS1-001 promoter in vivo. A ChIP assay was performed with U373MG cells treated with IL-1 $\beta$. Chromatin of U373MG cells was separately immunoprecipitated with specific antibody against CEBPD (CD) and control IgG [14]. The schematic on the top indicated the location of the primers used for detection of the GLYCTK-AS1-001 promoter by PCR. The precipitated DNAs were amplified by PCR with primer (FR-211) on the GLYCTK-AS1-001 promoter $(-98 /+113)$ which contain putative CEBPD-binding motif and negative control primer (FR-250). The data represented the mean \pm standard error of three independent experiments, each performed in triplicate. $\left({ }^{*} P<0.05, * * P<0.01, * * * P<0.001\right.$, Student's $t$ test)

surrounding A $\beta$ plagues [26, 20]. We found that AppTg/ $\mathrm{Cebpd}^{-1-}$ mice showed a spatial learning improvement compared with the AppTg mice. The Cebpd-deficient neuron was not found to play a role in inflammation-induced apoptosis. Since astrocytes are critical glial cells to support CNS by providing neurotrophic factors, we therefore tested whether certain neurotrophic factors were lost in activated astrocytes in response to proinflammatory factors. The neurotrophic factor THBS1 secreted from astrocytes was found to be attenuated in IL- $1 \beta$-treated astrocytes. We also found that the activation of miR-135a transcription was responsive to transcription factor CEBPD and represses THBS1 abundance in astrocytes. In addition to our recent discovery that miR135a plays an angiogenic role [27], we further demonstrated that astrocytic miR-135a participates in inhibition of neuronal viability and spatial learning ability in App$\mathrm{Tg}$ mice. We found that $A p p \mathrm{Tg}$ mice treated with 
A
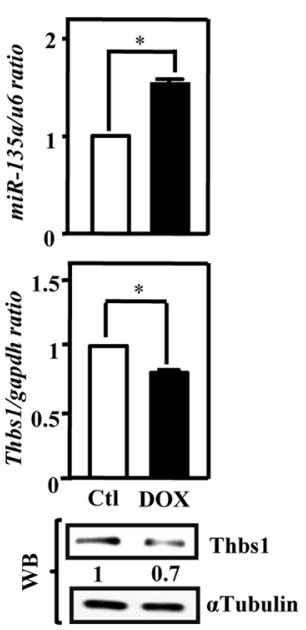

D

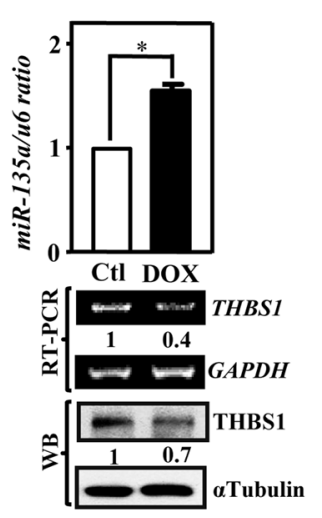

B
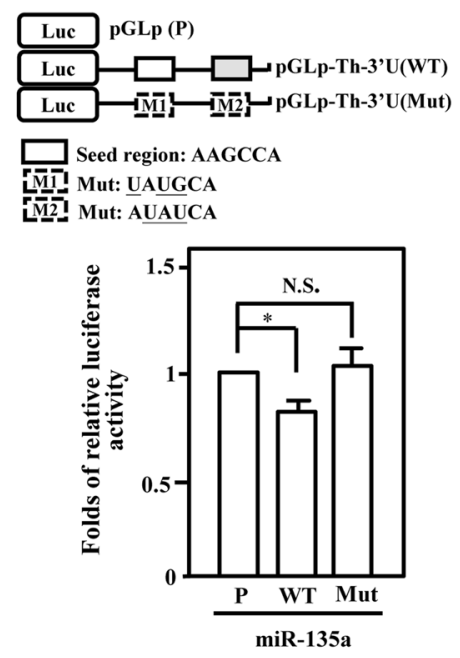

$\mathbf{E}$

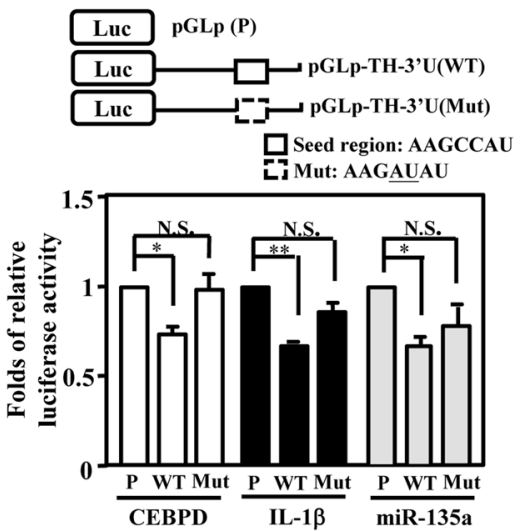

C

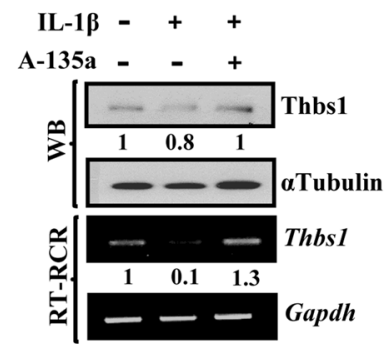

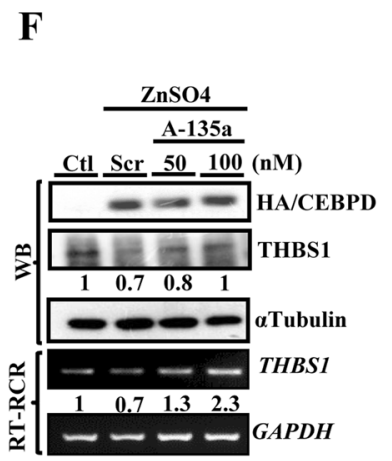

Fig. 4 miR-135a suppresses Thbs1/THBS1 transcription through its $3^{\prime}$ UTR region. a miR-135a attenuates the expression of Thbs1. Induced miR135a in primary astrocytes with DOX-inducible miR-135a expression system; qRT-PCR and western blot analysis confirmed that miR135a, Thbs 1 mRNAs, and proteins levels, respectively. b Two positions of the Thbs1 3'-untranslated region are predicted to be targets of miR135a. The seed regions were indicated by the open box (upper panel). Luciferase activity of reporter constructs was measured after cotransfected with pre-miR-135a. c Antisense of miR135a (A-135a) antagonize the effects of Cebpd. Induced A-135a in primary astrocytes with IPTG-inducible A-135a expression system and treated with or without IL-1 $\beta$ treatment. d Induced miR-135a expression repress the THBS1 expression. In stable U373MG cells with DOX-inducible miR-135a expression system, the expression of miR-135a and the level of THBS1

AM135a had less dead neurons and showed improvement in spatial learning ability.

Cebpd ${ }^{1-}$ mice are viable and have normal spatial learning ability as compared to wild-type mice [35]. However, the loss of Cebpd was found to delay the progression and pathogenesis of some inflammatory diseases $[23,25]$. It implies that CEBPD may not be essential in normal development, but can play important roles in the pathogenesis of inflammatory diseases. However, the details of CEBPD biology in
mRNAs and proteins were examined by qRT-PCR, RT-PCR, and Western blot, respectively. e IL-1 $\beta$ and CEBPD suppresses THBS1 transcription via miR-135a binding motif. The seed region was indicated by the open box (upper panel). Luciferase activity of reporter constructs was measured after co-transfected with pre-miR-135a, CEBPD expression vectors, or treated IL-1 $\beta$. f Antagomir of miR135a (AM135a) dose-dependently antagonized the effects of CEBPD. AM135a or scramble antagomir were transfected into the U373MG stable cells with zinc-inducible CEBPD expression system and then incubated in the presence or absence of $100 \mu \mathrm{M}$ ZnSO4 for $6 \mathrm{~h}$. RT-PCR and Western blot analysis were performed to examine the expressions of THBS1 mRNA and protein. The data represent the mean \pm standard error of three independent experiments, each performed in triplicate. $(* P<0.05, * * P<0.01$, Student's $t$ test $)$

inflammation and inflammation-associated diseases remain largely uninvestigated. Inflammation has been associated with many neuronal diseases including AD, Parkinson's disease (PD), spinal cord injury, amyotrophic lateral sclerosis, and multiple sclerosis [1]. Common physiological consequents including the memory loss, dementia, and cognitive impairment have been observed in many neuroinflammatory diseases such as AD, Parkinson's and Huntington's disease (HD) [36]. However, as mentioned above, the crosstalks, especially in 
A

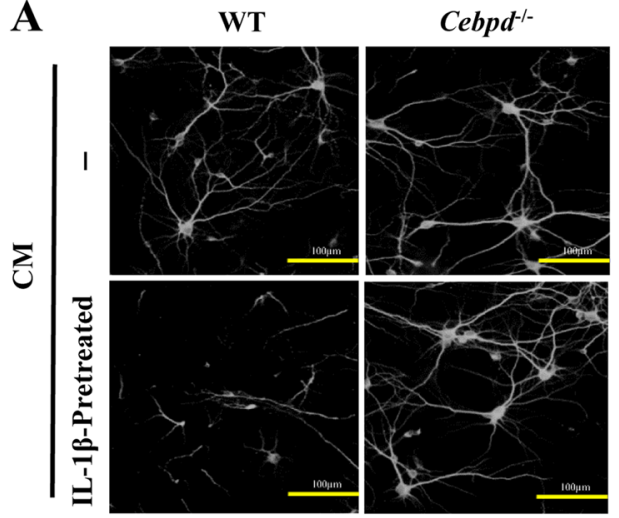

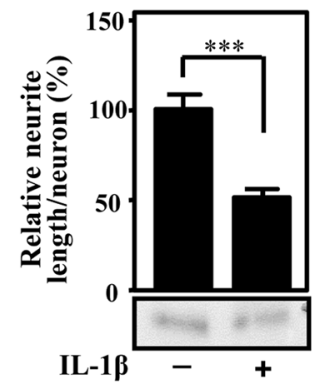

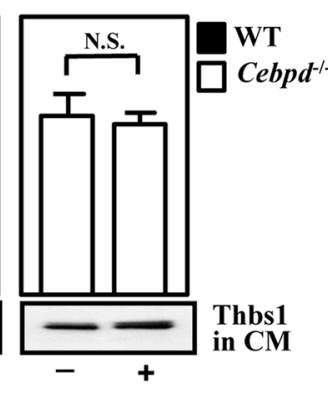

B
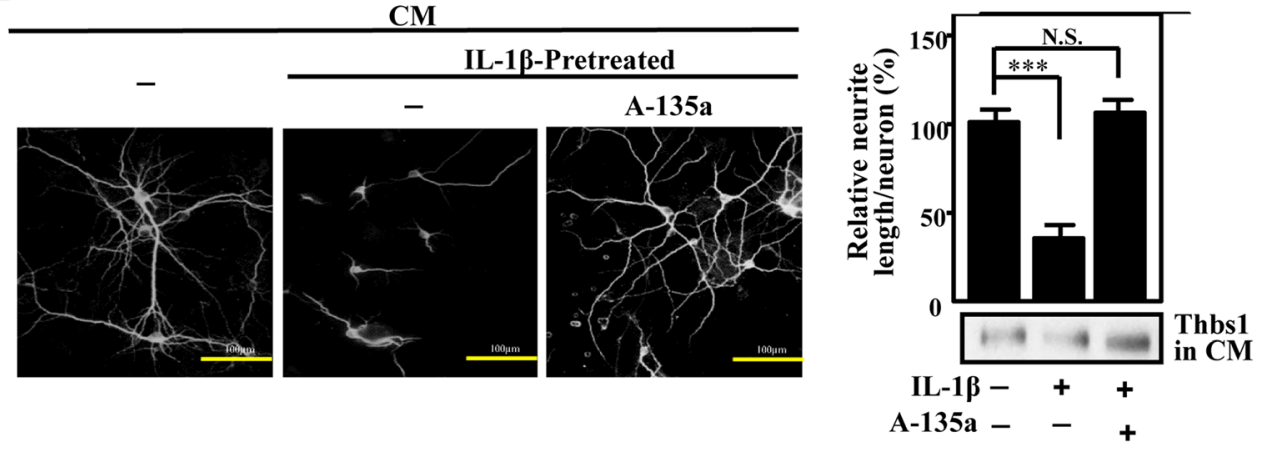

Fig. 5 Astrocytic CEBPD and miR-135a regulate the extension of primary cortical neurons. a CEBPD in astrocytes reduces neuronal neurite length. Conditioned medium from primary $\mathrm{Cebpd}^{+/+}$or $\mathrm{Cebpd}^{-/}$astrocytes with or without IL-1 $\beta$ treatment were subjected to exam Thbs1 by Western blot and added to primary neurons for $48 \mathrm{~h}$. b Attenuated miR$135 \mathrm{a}$ in astrocytes restore the neuronal neurite outgrowth. Conditioned medium from primary astrocytes infected with IPTG-inducible A-135a

response to the activation of astrocytic CEBPD, between astrocytes and neurons in the inflamed brains have not been characterized.

Previously, we provided evidences to demonstrate that the activation of astrocytic CEBPD can contribute to inhibition of phagocytosis, promotion of microglia migration, and chemoattraction $[26,24]$. The reduced extracellular level of astrocytic THBS1 could be caused by amyloid-beta $(\mathrm{A} \beta)$ and in Down syndrome, a disorder with a strong predilection for the development of $\operatorname{AD}[37,38]$. Our study showed a coincident result that the THBS1 abundance is attenuated in AD patients [39]. Accordingly, decreased neuronal neurite outgrowth, survival, and synaptophysin levels were also reported to be associated with both knock down or knock out of THBS1 [40, 37]. We found that the activation of astrocytic CEBPD contributed to repression of neurotrophic factor THBS1 abundance, which could result in the shortened neurite length and death of neurons. Moreover, we revealed that the CEBPD-upregulated miR-135a can target to THBS1$3^{\prime} \mathrm{UTR}$ and resulted in its mRNA and protein degradations.

Dystrophic neurites are a hallmark in the brain of AD and associated with mental decline and dementia [41]. Previous expression system with or without IL-1 $\beta$ treatment were subjected to exam Thbs1 by Western blot and added to primary neurons for $48 \mathrm{~h}$. Neurons were stained with mouse anti-MAP2 Abs for morphological examination. Scale bar $=100 \mu \mathrm{m}$. ImageJ software was used to quantification micrometers of neurite length /neuron. Quantification of relative of neurite length/neuron. $\left({ }^{*} P<0.05, * * P<0.01\right.$, Student's $t$ test)

Fig. 6 The in vivo effects of AM 135a. a miR-135a expression increase in the brain tissues of AppTg mice. miR-135a signal was detected by in situ hybridization in the hippocampus and cortex of WT, AppTg, and AppTg/Cebpd ${ }^{-1}$ mice. Scale bar $=200 \mu \mathrm{m}$. b Cy3-AM135a efficiently injected into $A p p T g$ mice. Twelve-month-old $A p p T g$ mice were injected in the third ventricle with Cy3-labeled AM135a. At $24 \mathrm{~h}$, fluorescence for Cy3-AM135a was distributed throughout the hippocampus and surrounding tissues. Cy3 fluorescence was not detected in control (noninjected) brains. Insets show magnified views of the regions indicated with arrows. Nuclei were stained with DAPI. c AM135a significantly increased the whole brain level of Thbs1. Western blot analysis conducted to detect Thbs 1 of AppTg mice injected with AM135a and the scramble antagomir at 1 week after the injection. d AM135a improved the spatial learning ability of App Tg mice. Intraventricular injected AppTg mice of AM135a (AppTg-AM135a) or scramble antagomir (AppTg-Scramble). Morris water maze test for spatial learning were performed 1 week after injection. Time required by WT $(n=5)$, AppTg-AM135a $(n=5)$, and AppTg-Scramble $(n=5)$ mice to reach the hidden platform (latency to hidden) were analyzed. e Cleavage caspase 3 (cCap3) expression was reduced in App Tg mice treated with AM135a. The brain tissues were subjected to immunofluorescence with anti-NeuN and anti-cleaved caspase 3 (cCap3). Scale bar $=100 \mu \mathrm{m}$. Data are expressed as mean \pm SEM by a Student's $t$ test. $\left({ }^{*} P<0.05 ;{ }^{* *} P<0.01 ; * * * P<0.001 ; N S\right.$ not significant) 
A
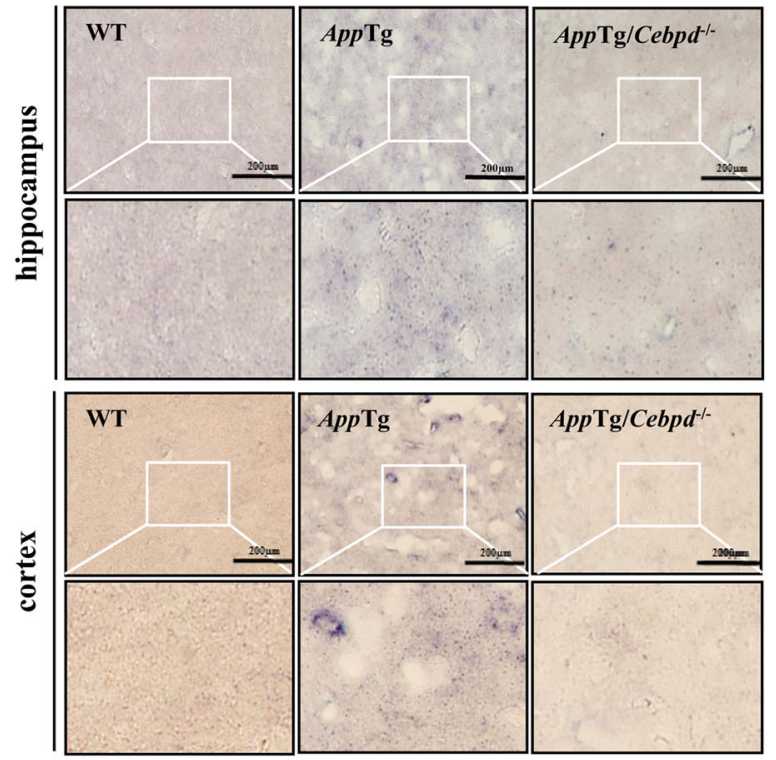

B

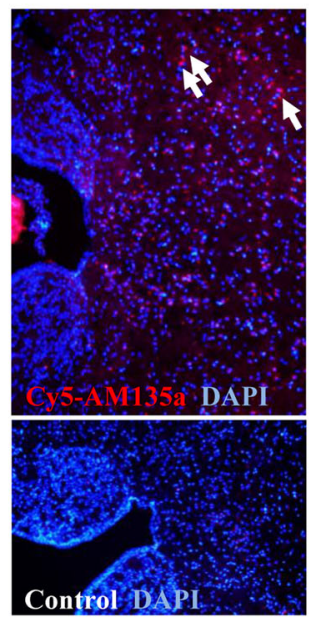

C

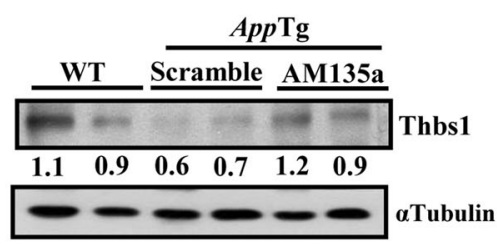

D

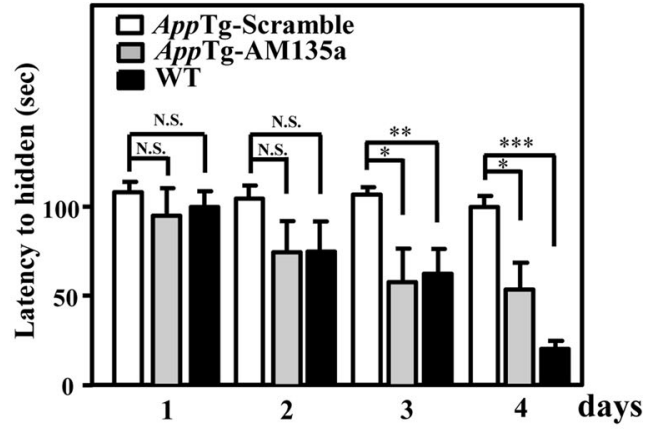

$\mathbf{E}$

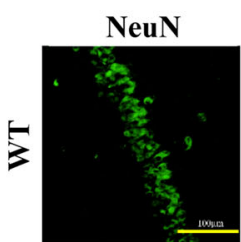

cCap3
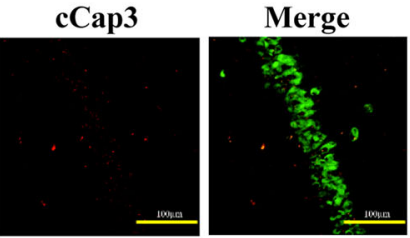

DAPI
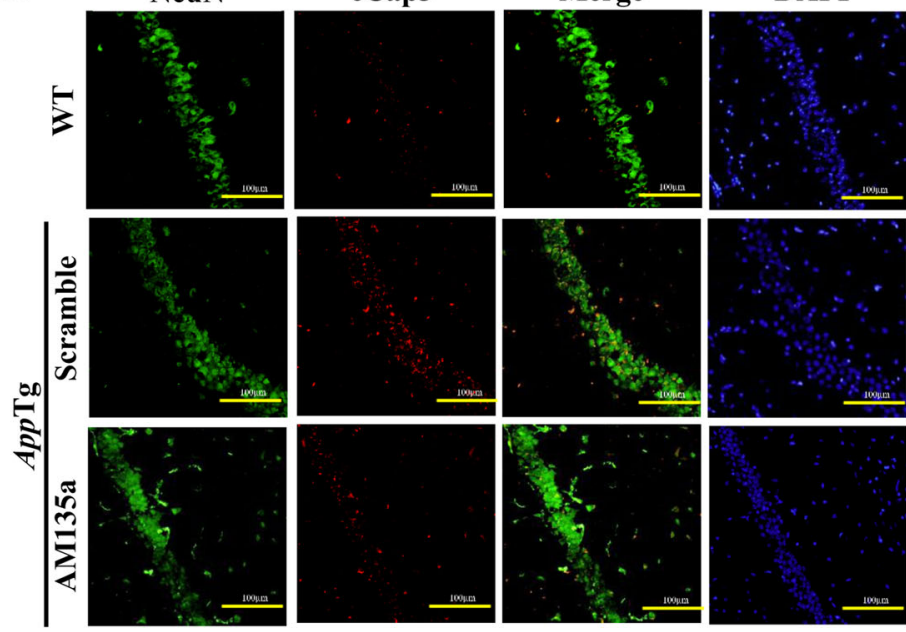

studies showed that $A \beta$ contribute to neurite degeneration in cultured neurons and ultimately result in neuronal death $[42$, 43]. In addition to proinflammatory cytokines IL-1 $\beta$ and $\mathrm{TNF} \alpha$, the treatment of $\mathrm{A} \beta$ also induced CEBPD activation in astrocytes [26]. The results of neurons growing in the CM from astrocyte expressing CEBPD or miR-135a provided a novel mechanism to explain the reduced neuronal neurite length and survival commonly observed in $\mathrm{AD}$ or other neuroinflammatory diseases. It also provided a new evidence for the communication between astrocytes and neuron in inflamed brain, especially in astrocyte-mediated cognitive loss. Moreover, AM135a, the antagomir neutralizing miR-135a, 
could enhance THBS1 levels to prevent neuronal loss and improve the learning ability in AppTg mice. The results indicated that administration of AM135a could be a therapeutically effective treatment for $\mathrm{AD}$ patients.

Previous studies have identified that several miRNAs in the brain are associated with $\mathrm{AD}, \mathrm{HD}, \mathrm{PD}$, neuroviral infections, and schizophrenia [44, 45]. Upregulation of miR-135a was detected in the cerebrospinal fluid (CSF) of AD patients and a microarray profile of the brain of $\mathrm{AD}$ mice $[46,47]$. miR$135 \mathrm{a}$ is a novel CEBPD responsive gene and first identified to regulate THBS1 transcription. The results showed the first evidence of miRNA-dependent dysregulation of THBS1 gene involved in the pathogenesis of AD. Consistent with previous studies [46, 47], our in situ hybridization result also demonstrated that miR-135a was increased in the cortex and hippocampus of AppTg mice. Whereas, a recent study showed that miR-135a targeted to beta-site amyloid precursor proteincleaving enzyme 1 (BACE1) in neuron cells and downregulated in CSF and serum of AppTg mice [48]. The inconsistent results indicated that the regulation of miR-135a could be in a cell-type specific manner or because the variations of specimens of $\mathrm{AD}$ patients and age of the AppTg mice. In addition, BACE1 is majorly expressed and function in neuron cells. However, miR-135a is a glia-enriched miRNA and low in normal neuron cells [49]. Therefore, the contribution and impact of miR-135a-mediated BACE1 repression in AD patients need to be further verified.

In this study, we provided a result of CEBPD-regulated miRNAs in astrocytes (Table 2). In addition to miR-135a, several CEBPD-downregulated miRNAs including miR-9, miR-19b, miR-29a/b-1, miR-16, and miR-107 were found to be repressed in neurodegenerative diseases [50, 51]. Among them, the expression level of miR-9, miR-29a/b-1, and miR107 was also reported to be negatively correlated with BACE1 in AD pathogenesis [52-54]. The attenuation of miR-9 and miR-29a were further found in HD mice, which resulted in the increase of transcription factor REST, a repressor of neurotrophic factor $B D N F$ transcription [31]. In addition, with respect to PD, miR-19b, miR-29a, and miR-16 were decreased in sporadic and familial late-onset PD [55]. However, the specific location and regulation of above miRNAs in brain and their specific function in astrocytes still pose an open question for a further investigation. Furthermore, the links between CEBPD responsive miRNAs and putative downstream genes (Table 2) also provide interesting candidates for inhibiting release of neurotrophic factors or producing neurotoxins. Artemin (ARTN) is a potent neurotrophic factor for the peripheral nervous system and has great potential for the treatment of neuropathic pain [56]. We found that miR-1914 could be induced by CEBPD and is predicted to target the ARTN 3'UTR region. In addition, neurotoxic factor nitric oxide generated via iNOS was found in postmortem brains of AD and PD patients [57]. CEBPD reduced the levels of miR-26b, miR- 29a, and miR-128 that are predicted to target inducible nitric oxide synthase [10]. Therefore, the dissection of astrocytic CEBPD involvement in inflamed brains that could reveal more details for puzzling the complex issues in neurodegenerative disorders.

Acknowledgements This work was supported from the grant MOST103-2321-B-006-031 and MOST103-2320-B-006-034-MY3 from the Ministry of Science and Technology. The authors have no conflicting financial interests.

\section{Compliance with Ethical Standards}

Conflict of Interest The authors declare that they have no conflict of interest.

Welfare of Animals The animal use protocol has been reviewed and approved by the Institutional Animal Care and Use Committee (IACUC) for this study (103132).

Open Access This article is distributed under the terms of the Creative Commons Attribution 4.0 International License (http:// creativecommons.org/licenses/by/4.0/), which permits unrestricted use, distribution, and reproduction in any medium, provided you give appropriate credit to the original author(s) and the source, provide a link to the Creative Commons license, and indicate if changes were made.

\section{References}

1. Glass CK, Saijo K, Winner B, Marchetto MC, Gage FH (2010) Mechanisms underlying inflammation in neurodegeneration. Cell 140(6):918-934. doi:10.1016/j.cell.2010.02.016

2. Akiyama H, Barger S, Barnum S, Bradt B, Bauer J, Cole GM, Cooper NR, Eikelenboom P et al (2000) Inflammation and Alzheimer's disease. Neurobiol Aging 21(3):383-421

3. Ikonomovic MD, Uryu K, Abrahamson EE, Ciallella JR, Trojanowski JQ, Lee VM, Clark RS, Marion DW et al (2004) Alzheimer's pathology in human temporal cortex surgically excised after severe brain injury. Exp Neurol 190(1):192-203. doi:10.1016/ j.expneurol.2004.06.011

4. Blennow K, de Leon MJ, Zetterberg H (2006) Alzheimer's disease. Lancet 368(9533):387-403. doi:10.1016/s0140-6736(06)69113-7

5. Palop JJ, Mucke L (2010) Amyloid-beta-induced neuronal dysfunction in Alzheimer's disease: from synapses toward neural networks. Nat Neurosci 13(7):812-818. doi:10.1038/nn.2583

6. Simpson JE, Ince PG, Lace G, Forster G, Shaw PJ, Matthews F, Savva G, Brayne C, Wharton SB Astrocyte phenotype in relation to Alzheimer-type pathology in the ageing brain. Neurobiology of aging 31 (4):578-590. 10.1016/j.neurobiolaging.2008.05.015 [doi]

7. Pekny M, Nilsson M (2005) Astrocyte activation and reactive gliosis. Glia 50(4):427-434. doi:10.1002/glia.20207

8. Tuppo EE, Arias HR (2005) The role of inflammation in Alzheimer's disease. Int J Biochem Cell Biol 37(2):289-305. doi: 10.1016/j.biocel.2004.07.009

9. Solecki DJ, Model L, Gaetz J, Kapoor TM, Hatten ME (2004) Par6alpha signaling controls glial-guided neuronal migration. Nat Neurosci 7(11):1195-1203. doi:10.1038/nn1332

10. Voutsinos-Porche B, Bonvento G, Tanaka K, Steiner P, Welker E, Chatton JY, Magistretti PJ, Pellerin L (2003) Glial glutamate 
transporters mediate a functional metabolic crosstalk between neurons and astrocytes in the mouse developing cortex. Neuron 37(2):275-286

11. Ransom B, Behar T, Nedergaard M (2003) New roles for astrocytes (stars at last). Trends Neurosci 26(10):520-522. doi:10.1016/j.tins. 2003.08.006

12. Adams JC (2001) Thrombospondins: multifunctional regulators of cell interactions. Annu Rev Cell Dev Biol 17:25-51. doi:10.1146/ annurev.cellbio.17.1.25

13. Lu Z, Kipnis J (2010) Thrombospondin 1-a key astrocyte-derived neurogenic factor. Faseb J 24(6):1925-1934. doi:10.1096/fj.09150573

14. Osterhout DJ, Frazier WA, Higgins D (1992) Thrombospondin promotes process outgrowth in neurons from the peripheral and central nervous systems. Dev Biol 150(2):256-265

15. Christopherson KS, Ullian EM, Stokes CC, Mullowney CE, Hell JW, Agah A, Lawler J, Mosher DF et al (2005) Thrombospondins are astrocyte-secreted proteins that promote CNS synaptogenesis. Cell 120(3):421-433. doi:10.1016/j.cell.2004.12.020

16. Ramji DP, Foka P (2002) CCAAT/enhancer-binding proteins: structure, function and regulation. Biochem J 365(Pt 3):561-575. doi: 10.1042/bj20020508

17. Cardinaux JR, Allaman I, Magistretti PJ (2000) Pro-inflammatory cytokines induce the transcription factors C/EBPbeta and C/ EBPdelta in astrocytes. Glia 29(1):91-97. doi:10.1002/(SICI) 1098-1136(20000101)29:1<91::AID-GLIA9>3.0.CO;2-I

18. Ramji DP, Vitelli A, Tronche F, Cortese R, Ciliberto G (1993) The two C/EBP isoforms, IL-6DBP/NF-IL6 and C/EBP delta/NF-IL6 beta, are induced by IL- 6 to promote acute phase gene transcription via different mechanisms. Nucleic Acids Res 21(2):289-294

19. Lucas SM, Rothwell NJ, Gibson RM (2006) The role of inflammation in CNS injury and disease. Br J Pharmacol 147(Suppl 1):S232S240. doi:10.1038/sj.bjp.0706400

20. Li R, Strohmeyer R, Liang Z, Lue LF, Rogers J (2004) CCAAT/ enhancer binding protein delta (C/EBPdelta) expression and elevation in Alzheimer's disease. Neurobiol Aging 25(8):991-999. doi: 10.1016/j.neurobiolaging.2003.10.016

21. Yang ZH, Kitami Y, Takata Y, Okura T, Hiwada K (2001) Targeted overexpression of CCAAT/enhancer-binding protein-delta evokes enhanced gene transcription of platelet-derived growth factor alphareceptor in vascular smooth muscle cells. Circ Res 89(6):503-508

22. Bennett CE, Nsengimana J, Bostock JA, Cymbalista C, Futers TS, Knight BL, McCormack LJ, Prasad UK et al (2010) CCAAT/ enhancer binding protein alpha, beta and delta gene variants: associations with obesity related phenotypes in the Leeds Family Study. Diab Vasc Dis Res 7(3):195-203. doi:10.1177/1479164110366274

23. Chang LH, Huang HS, Wu PT, Jou IM, Pan MH, Chang WC, Wang DD, Wang JM (2012) Role of macrophage CCAAT/enhancer binding protein delta in the pathogenesis of rheumatoid arthritis in collagen-induced arthritic mice. PLoS One 7(9), e45378. doi:10. 1371/journal.pone.0045378

24. Ko CY, Wang WL, Wang SM, Chu YY, Chang WC, Wang JM (2014) Glycogen synthase kinase-3beta-mediated CCAAT/ enhancer-binding protein delta phosphorylation in astrocytes promotes migration and activation of microglia/macrophages. Neurobiol Aging 35(1):24-34. doi:10.1016/j.neurobiolaging. 2013.07.021

25. Wang SM, Lee YC, Ko CY, Lai MD, Lin DY, Pao PC, Chi JY, Hsiao YW et al (2014) Increase of zinc finger protein 179 in response to CCAAT/enhancer binding protein delta conferring an antiapoptotic effect in astrocytes of Alzheimer's disease. Mol Neurobiol. doi:10.1007/s12035-014-8714-9

26. Ko CY, Chang LH, Lee YC, Sterneck E, Cheng CP, Chen SH, Huang AM, Tseng JT et al (2012) CCAAT/enhancer binding protein delta (CEBPD) elevating PTX3 expression inhibits macrophage-mediated phagocytosis of dying neuron cells.
Neurobiol Aging 33(2):e411-425. doi:10.1016/j.neurobiolaging. 2010.09.017

27. Ko CY, Chu YY, Narumiya S, Chi JY, Furuyashiki T, Aoki T, Wang SM, Chang WC et al (2014) The CCAAT/enhancer-binding protein delta/miR135a/thrombospondin 1 axis mediates PGE2-induced angiogenesis in Alzheimer's disease. Neurobiol Aging. doi:10.1016/j. neurobiolaging.2014.11.020

28. Bartel DP (2009) MicroRNAs: target recognition and regulatory functions. Cell 136(2):215-233. doi:10.1016/j.cell.2009.01.002

29. Eacker SM, Dawson TM, Dawson VL (2009) Understanding microRNAs in neurodegeneration. Nat Rev Neurosci 10(12):837841. doi:10.1038/nrn2726

30. Kim J, Inoue K, Ishii J, Vanti WB, Voronov SV, Murchison E, Hannon G, Abeliovich A (2007) A MicroRNA feedback circuit in midbrain dopamine neurons. Science(NY) 317(5842):1220-1224. doi:10.1126/science.1140481

31. Packer AN, Xing Y, Harper SQ, Jones L, Davidson BL (2008) The bifunctional microRNA miR-9/miR-9* regulates REST and CoREST and is downregulated in Huntington's disease. $\mathrm{J}$ Neurosci 28(53):14341-14346. doi:10.1523/jneurosci.239008.2008

32. Ziu M, Fletcher L, Rana S, Jimenez DF, Digicaylioglu M (2011) Temporal differences in microRNA expression patterns in astrocytes and neurons after ischemic injury. PLoS One 6(2), e14724. doi:10.1371/journal.pone.0014724

33. Milner R, Campbell IL (2002) Cytokines regulate microglial adhesion to laminin and astrocyte extracellular matrix via protein kinase C-dependent activation of the alpha6betal integrin. J Neurosci 22(5):1562-1572

34. Wang JM, Ko CY, Chen LC, Wang WL, Chang WC (2006) Functional role of NF-IL6beta and its sumoylation and acetylation modifications in promoter activation of cyclooxygenase 2 gene. Nucleic Acids Res 34(1):217-231. doi:10.1093/nar/gkj422

35. Sterneck E, Paylor R, Jackson-Lewis V, Libbey M, Przedborski S, Tessarollo L, Crawley JN, Johnson PF (1998) Selectively enhanced contextual fear conditioning in mice lacking the transcriptional regulator CCAAT/enhancer binding protein delta. Proc Natl Acad Sci U S A 95(18):10908-10913

36. Massman PJ, Delis DC, Butters N, Levin BE, Salmon DP (1990) Are all subcortical dementias alike? Verbal learning and memory in Parkinson's and Huntington's disease patients. J Clin Exp Neuropsychol 12(5):729-744. doi:10.1080/01688639008401015

37. Garcia O, Torres M, Helguera P, Coskun P, Busciglio J (2010) A role for thrombospondin-1 deficits in astrocyte-mediated spine and synaptic pathology in Down's syndrome. PLoS One 5(12), e14200. doi:10.1371/journal.pone.0014200

38. Rama Rao KV, Curtis KM, Johnstone JT, Norenberg MD (2013) Amyloid-beta inhibits thrombospondin 1 release from cultured astrocytes: effects on synaptic protein expression. J Neuropathol Exp Neurol 72(8):735-744. doi:10.1097/NEN. 0b013e31829bd082

39. Buee L, Hof PR, Roberts DD, Delacourte A, Morrison JH, Fillit HM (1992) Immunohistochemical identification of thrombospondin in normal human brain and in Alzheimer's disease. Am J Pathol 141(4):783-788

40. Yu K, Ge J, Summers JB, Li F, Liu X, Ma P, Kaminski J, Zhuang J (2008) TSP-1 secreted by bone marrow stromal cells contributes to retinal ganglion cell neurite outgrowth and survival. PLoS One 3(6), e2470. doi:10.1371/journal.pone.0002470

41. Su JH, Cummings BJ, Cotman CW (1993) Identification and distribution of axonal dystrophic neurites in Alzheimer's disease. Brain Res 625(2):228-237

42. Ivins KJ, Bui ET, Cotman CW (1998) Beta-amyloid induces local neurite degeneration in cultured hippocampal neurons: evidence for neuritic apoptosis. Neurobiol Dis 5(5):365-378. doi:10.1006/nbdi. 1998.0228 
43. Abad MA, Enguita M, DeGregorio-Rocasolano N, Ferrer I, Trullas R (2006) Neuronal pentraxin 1 contributes to the neuronal damage evoked by amyloid-beta and is overexpressed in dystrophic neurites in Alzheimer's brain. J Neurosci 26(49):12735-12747. doi:10. 1523/jneurosci.0575-06.2006

44. Thounaojam MC, Kaushik DK, Basu A (2013) MicroRNAs in the brain: it's regulatory role in neuroinflammation. Mol Neurobiol 47(3):1034-1044. doi:10.1007/s12035-013-8400-3

45. Lau P, de Strooper B (2010) Dysregulated microRNAs in neurodegenerative disorders. Semin Cell Dev Biol 21(7):768-773. doi:10. 1016/j.semcdb.2010.01.009

46. Lee ST, Chu K, Jung KH, Kim JH, Huh JY, Yoon H, Park DK, Lim $J Y$ et al (2012) miR-206 regulates brain-derived neurotrophic factor in Alzheimer disease model. Ann Neurol 72(2):269-277. doi:10. 1002/ana.23588

47. Cogswell JP, Ward J, Taylor IA, Waters M, Shi Y, Cannon B, Kelnar K, Kemppainen $J$ et al (2008) Identification of miRNA changes in Alzheimer's disease brain and CSF yields putative biomarkers and insights into disease pathways. J Alzheimers Dis 14(1):27-41

48. Liu CG, Wang JL, Li L, Xue LX, Zhang YQ, Wang PC (2014) MicroRNA-135a and -200b, potential biomarkers for Alzheimer's disease, regulate beta secretase and amyloid precursor protein. Brain Res. doi:10.1016/j.brainres.2014.04.026

49. Wu S, Lin Y, Xu D, Chen J, Shu M, Zhou Y, Zhu W, Su X et al (2012) MiR-135a functions as a selective killer of malignant glioma. Oncogene 31(34):3866-3874. doi:10.1038/onc.2011.551

50. Maciotta S, Meregalli M, Torrente Y (2013) The involvement of microRNAs in neurodegenerative diseases. Front Cell Neurosci 7: 265. doi: $10.3389 /$ fncel.2013.00265
51. Tan L, Yu JT, Tan L (2014) Causes and consequences of MicroRNA Dysregulation in neurodegenerative diseases. Mol Neurobiol. doi:10.1007/s12035-014-8803-9

52. Hebert SS, Horre K, Nicolai L, Papadopoulou AS, Mandemakers W, Silahtaroglu AN, Kauppinen S, Delacourte A et al (2008) Loss of microRNA cluster miR-29a/b-1 in sporadic Alzheimer's disease correlates with increased BACE1/beta-secretase expression. Proc Natl Acad Sci U S A 105(17):6415-6420. doi:10.1073/pnas. 0710263105

53. Wang WX, Rajeev BW, Stromberg AJ, Ren N, Tang G, Huang Q, Rigoutsos I, Nelson PT (2008) The expression of microRNA miR107 decreases early in Alzheimer's disease and may accelerate disease progression through regulation of beta-site amyloid precursor protein-cleaving enzyme 1. J Neurosci 28(5):1213-1223. doi:10. 1523/jneurosci.5065-07.2008

54. Hebert SS, De Strooper B (2009) Alterations of the microRNA network cause neurodegenerative disease. Trends Neurosci 32(4): 199-206. doi:10.1016/j.tins.2008.12.003

55. Martins M, Rosa A, Guedes LC, Fonseca BV, Gotovac K, Violante S, Mestre T, Coelho M et al (2011) Convergence of miRNA expression profiling, alpha-synuclein interacton and GWAS in Parkinson's disease. PLoS One 6(10), e25443. doi:10.1371/ journal.pone. 0025443

56. Baloh RH, Tansey MG, Lampe PA, Fahrner TJ, Enomoto H, Simburger KS, Leitner ML, Araki T et al (1998) Artemin, a novel member of the GDNF ligand family, supports peripheral and central neurons and signals through the GFRalpha3-RET receptor complex. Neuron 21(6):1291-1302

57. Kroncke KD, Fehsel K, Kolb-Bachofen V (1998) Inducible nitric oxide synthase in human diseases. Clin Exp Immunol 113(2):147-156 